\title{
The Impact of Trust and Cooperation on the Performance of PPP Projects: The Moderating Role of Risk Allocation
}

\author{
Chuanbin Zheng ${ }^{1,2+}$, Jingchun Feng ${ }^{1,3}$, Qianqian Lu ${ }^{4}$, Jianwei Zheng ${ }^{5}$, Ranran Chen ${ }^{1,2}$ and Song \\ Xue ${ }^{1,6}$ \\ ${ }^{1}$ Business School, Hohai University, Nanjing Jiangsu, 211100, China \\ ${ }^{2}$ Institute of Project Management of Hohai University, Nanjing Jiangsu, 211100, China \\ ${ }^{3}$ Jiangsu Provincial Collaborative Innovation Center of World Water Valley and Water Ecological \\ Civilization, Nanjing Jiangsu,211100, China \\ ${ }^{4}$ Children's hospital of Soochow University, Suzhou Jiangsu, 215025, China \\ ${ }^{5}$ Changjiang Polytechnic College, Wuhan Hubei, 430074, China \\ ${ }^{6}$ International River Research Centre of Hohai University, Nanjing Jiangsu, 211100, China
}

\begin{abstract}
Trust, cooperation, risk allocation and PPP project performance have been extensively investigated in literature. However, the impact of trust and cooperation on PPP project performance and the moderating role of risk allocation between them still lack empirical evidence. The present research attempts to bridge these gaps by using partial least squares (PLS) approach to analyze a sample of 216 valid responses. The results show that trust and cooperation positively affect PPP project performance, trust positively influences cooperation. Risk allocation improves the effects of trust and cooperation on PPP project performance, as well as improves the effect of trust on cooperation, and the cooperation plays partial mediate role between trust and PPP project performance. Therefore, the trust and cooperation play a key role in achieving PPP project performance while the moderating role of risk allocation should also be paid more attention. Research results can enrich the theory of relationship management (RM) and provide a theoretical reference to public sector and private sector for improvement of the performance by trust, cooperation, and risk allocation, and also in maintaining on-going relationships between them in the future.
\end{abstract}

Keywords: trust, cooperation, risk allocation, project performance

\section{Introduction}

Public-private partnership (PPP) can improve the efficiency of project management and enable them to provide high quality service and/or an asset. Thus, more and more countries have been actively inviting the private sectors to participate in constructing their infrastructure projects. However, PPP projects have not always achieved satisfactory outcomes and sometimes show a low success rate over the past decades. One significant obstacle for applying PPPs is concerned with the poor quality of the relationship between public and private sector, characterized by weaker cooperation, trust and risk allocation between the public sectors and the private sectors. Zou et al. (2014) [1] represented that RM is very important to improve the PPP project performance. More important, Cheung et al. (2011) [2] represented that trust was crucial to every transaction and it was the key driver in fostering cooperation. Based on previous research, it's said that cooperation on the average were more successful than traditional ones, and better performance can be achieved through cooperation.

Thus, trust and cooperation have an important role in achieving PPP project performance. However, when inappropriate risk allocation was present, most PPPs may fail. Considering that sometimes trust and

+ Corresponding author. Tel.: + 86 18512524956; fax: +021 68514622.

E-mail address: zcbdoc@126.com. 
cooperation may affect performance significantly while others may be insignificant, these issues have to be studied further. Therefore, it is important to analyze the impact of trust and cooperation on PPP project performance, and understand the role of risk allocation. We attempt to bridge these gaps through the guidance of the following research questions:

- How do trust, cooperation affect performance in PPP projects?

- How do trust affect cooperation in PPP projects?

- What is the relationship between trust, cooperation and PPP project performance?

- How do risk allocation modify the linkage between trust, cooperation and performance?

\section{Literature Review and Hypothesis}

\subsection{The impact of trust on performance}

For PPP projects, trust is very important to improve the PPP project performance. Zou et al. (2014) [1] said that trust is central to the quality of the relationship as well as alleviate adversarial relationships, Pinto et al. (2009) [3] concluded that trust as a facilitator of positive relationships among project stakeholders and had positively impact on project outcomes. Besides, trust is a fundamental ingredient of social interaction and has positive impact on performance [2], such as a reduction in cost of construction project. Kadefors (2004) [4] represented that higher level of trust would improve project performance, and Wong et al. (2008) [5] concluded that trust and performance had the very high correlation. Hence,

H1. Trust positively affects the PPP project performance.

\subsection{The relationship among trust, cooperation and performance in PPP projects}

In construction, trust was the critical factor for fostering cooperation. Wong and Cheung (2004) [6] concluded that trust has been seemed as the basic partnering, and it's helpful for project team members to communicate, share information as well as honour their commitments. Therefore, the trust is critical for realizing the cooperation of public sector and private sector. Thus:

H2. Trust positively affects cooperation.

Based on previous research, the results showed that cooperation on the average were more successful than traditional one. Robert et al. (2013) [7] confirmed that better performance can be achieved through cooperation. In addition, cooperation can facilitate the effective exchange of information and expertise of public sector and private sector. As such, PPP project performance can be largely improved. Therefore,

H3. Cooperation positively affects the PPP project performance.

\subsection{Moderating roles of risk allocation}

Trust and cooperation play important roles in achieving PPP project performance. However, when inappropriate risk allocation was present, most PPPs may fail. Cheung et al. (2012) [8] reported that appropriate allocation of risks in PPPs could improve the PPP success rate. In addition, trust has positive affects in appropriate allocation of risks, and appropriate allocation of risks has positive affects performance $[8,9]$.

Similarly, this type of risk allocation positively affects the influence of cooperation. Yet the inappropriate allocation of risks in PPPs affects private participation and the willing of cooperation. Thus better cooperation can be achieved through appropriate allocation of risks and trust-based relationships. What's more, Robert et al. (2013) [7] confirmed that better performance could be achieved through cooperative relationships. Therefore:

H4a. More appropriate risk allocation in PPP higher the positive affect of trust on performance.

H4b. More appropriate risk allocation in PPP higher the positive affect of trust on cooperation.

$\mathrm{H} 4 \mathrm{c}$. More appropriate risk allocation in PPP higher the positive affect of cooperation on performance.

\subsection{Control variable}

Three control variables, namely, project cost, duration, and industry type from PPP projects are applied in this research. McFarlan (1981) [10] confirmed that the project size influenced project performance, thus it 
was necessary to control the effect of the PPP projects' size. Besides, industry type of PPP project may also affect the performance. Fig. 1 brings all the above hypotheses together.

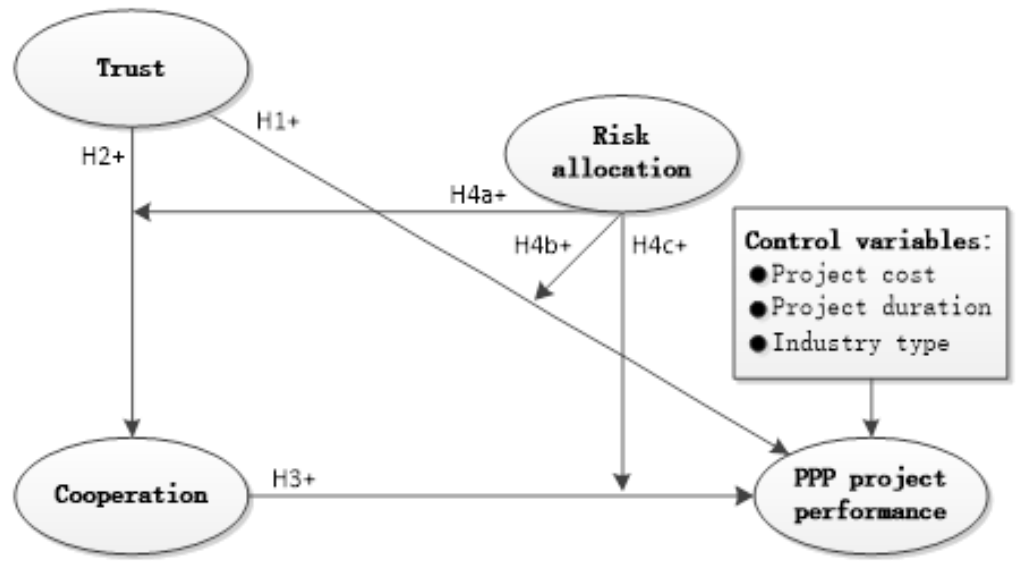

Fig. 1: Research model: trust, cooperation, risk allocation and performance.

\section{Research Methodology}

\subsection{Data collection}

Between January 2016 and May 2016, a total of 300 responses were received and the uncompleted ones had been deleted. As a result, the 216 remaining responses were found to be valid and could be used in the analysis. The response rate is $72 \%$.

\subsection{Measures}

We rely on existing measurement scales that have been validated in earlier studies. All items are designed with responses on a five-point Likert scale ranging from "strongly disagree (represented by 1)" to "strongly agree (represented by 5)." . Measures of trust we adapted from Suprapto et al. (2015) [11]. Measures of cooperation were based on scales presented by Liu and Wang (2015) [12]. Risk allocation items were based on scales presented by Ke et al. (2010) [13]. PPP project performance items were based on scales presented by Suprapto et al. (2015) [11].

\section{Results}

\subsection{Reliability and validity}

Firstly, we examined reliability. It's widely acknowledged that Cronbach's $\alpha$ is adopted to test reliability, the values of Cronbach's $\alpha$ is higher than 0.8, thus indicating that the reliability is good. Secondly, we checked convergent validity and discriminant validity. All cross loadings are higher than 0.80 and exceeds the loadings between other constructs and the items. Besides, the other loadings are lower than 0.50, which means convergent validity and discriminant validity are good.

\subsection{Hypothesis testing}

As shown in model 1 of Table 4, the control variables (project duration, cost and industrial type) insignificantly influence the performance of PPP projects. Thus, the performance of PPP projects does not differ in terms of project duration, cost and industrial type. As shown in model 4 and 5 of Table 4, the path coefficients of trust and cooperation with performance are significant. Besides, as shown in model 2 of Table 4 , the path coefficients of trust with cooperation are also significant. Significant incremental variance $\left(\Delta \mathrm{R}^{2}=\right.$ $13 \%$ ) was explained for the dependent variable. Therefore, $\mathrm{H} 1, \mathrm{H} 2$, and $\mathrm{H} 3$ are supported.

Models 3, 7, and 8 display significant variance for the dependent variable. The interaction terms between trust and risk allocation, cooperation and risk allocation are positive and significant. The results show that the effects of trust on cooperation are positively moderated by risk allocation, and the effects of trust and cooperation on PPP project performance are positively moderated by risk allocation. An excess of $4 \%$ to $8 \%$ of explained variance in the dependent variable is produced by the interaction terms. Thus, all 
moderating effects are significant. The significance level of $\mathrm{F}$ hierarchical in each model further validates the results. Therefore, $\mathrm{H} 4 \mathrm{a}, \mathrm{H} 4 \mathrm{~b}$ and $\mathrm{H} 4 \mathrm{c}$ are supported.

We adopted the approach of Wen and Ye (2014) [14] to examine that the cooperation played mediating role between trust and performance. Firstly, the interaction terms between trust and PPP project performance are positive and significant. Secondly, the interaction terms between trust and cooperation and the interaction terms between cooperation and PPP project performance are positive and significant. Thirdly, the effects of trust and cooperation on PPP project performance are positive and significant. In conclusion, the results shows that the cooperation plays partial mediating role between trust and performance.

Table 1: Hierarchical regression results.

\begin{tabular}{|c|c|c|c|c|c|c|c|c|}
\hline \multirow{3}{*}{$\begin{array}{l}\text { Relation } \\
\text { To } \\
\text { From }\end{array}$} & \multicolumn{8}{|l|}{ Outcome } \\
\hline & \multirow{2}{*}{$\begin{array}{l}\text { Performance } \\
\text { Model } 1\end{array}$} & \multicolumn{2}{|c|}{ Cooperation } & \multicolumn{5}{|c|}{ Performance } \\
\hline & & Model 2 & Model 3 & Model 4 & Model 5 & Model 6 & Model 7 & Model 8 \\
\hline \multicolumn{9}{|c|}{ Block 1: Control variables } \\
\hline $\begin{array}{l}\text { Project } \\
\text { duration }\end{array}$ & -0.06 & -0.07 & -0.05 & -0.04 & -0.06 & -0.07 & -0.08 & -0.05 \\
\hline Project cost & 0.08 & 0.09 & 0.11 & 0.12 & 0.12 & 0.10 & 0.11 & 0.13 \\
\hline Industrial type & -0.07 & -0.06 & -0.04 & -0.05 & -0.07 & -0.08 & -0.09 & -0.06 \\
\hline $\begin{array}{l}\text { Block 2: Main } \\
\text { Trust }\end{array}$ & fects & $0.36^{* * *}$ & $0.42^{* * *}$ & $0.57^{* * *}$ & & $0.52^{* * * *}$ & $0.54^{* * *}$ & \\
\hline $\begin{array}{l}\text { Cooperation } \\
\text { Risk allocation } \\
\text { Block 3: Mode }\end{array}$ & tion effects & & -0.02 & & $0.40^{* * * *}$ & $0.21^{* * *}$ & $0.13^{*}$ & $\begin{array}{l}0.33^{* * *} \\
0.33^{* * * *}\end{array}$ \\
\hline $\begin{array}{l}\text { Trust } \times \text { Risk } \\
\text { allocation }\end{array}$ & & & $0.28^{* * * *}$ & & & & $0.21^{* * * *}$ & \\
\hline $\begin{array}{l}\text { Cooperation } \times \\
\text { Risk allocation }\end{array}$ & & & & & & & & $0.27^{* * *}$ \\
\hline $\mathrm{F}$ & & $32.28^{* * * *}$ & $18.46^{* * *}$ & $102.56^{* * * *}$ & $40.01^{* * * *}$ & $68.21^{* * *}$ & $48.26^{* * *}$ & $42.77^{* * *}$ \\
\hline $\mathrm{R}^{2}$ & & 0.13 & 0.21 & 0.32 & 0.16 & 0.39 & 0.41 & 0.38 \\
\hline${ }_{\Delta \mathrm{F}} \mathrm{s}$ & & $32.28^{* * *}$ & $20.27^{* * *}$ & $102.56^{* * *}$ & $40.01^{* * * *}$ & $68.21^{* * *}$ & $15.79^{* * *}$ & $23.92^{* * *}$ \\
\hline$\Delta R^{2}$ & 0.046 & 0.13 & 0.08 & 0.32 & 0.16 & 0.39 & 0.04 & 0.07 \\
\hline
\end{tabular}

\section{Conclusions}

This research provides some important insights into existing literature by trust, cooperation and risk allocation and performance in PPP projects. Firstly, this research finds that trust and cooperation positively affect the PPP project performance, and trust positively affects cooperation. It is supported that trust, cooperation, and risk allocation have an important role in PPP project performance. Besides, the results show that risk allocation has moderating roles in the correlation of trust with cooperation, trust with PPP project performance, and cooperation with PPP project performance. In addition, risk allocation improves the effects of trust and cooperation on PPP project performance, and the effect of trust on cooperation in PPP projects. Furthermore, this study applies a mediation model to check that the cooperation plays partial mediate role between trust and PPP project performance, which suggests that we should strength the cooperation of the public sector and private sector in order to promote trust with each other.

\section{Acknowledgements}

This study was supported by the grants from Key National Social Science Foundation of China (Grant No.14AZD024), Study on the Cooperative Supervision Pattern of PPP Project under Market Decisive Function (Grant No.15CJL023), and the central university basic research business expenses special funds (Grant No.2013B15020062,2014B09014,2015B08214,2016B03914).

\section{References}

[1] W. Zou, M. Kumaraswamy, J. Chung, and J. Wong. Identifying the critical success factors for relationship management in PPP projects. Int J Proj Manage. 2014, 32(2): 265-274. 
[2] S. Cheung, W. Wong, T. Yiu, and H. Pang. Developing a Trust Inventory for Construction Contracting. Int J Proj Manage. 2011, 29(3): 184-196.

[3] J. Pinto, D. Slevin, and B. English. Trust in projects: an empirical assessment of owner/contractor relationships. Int J Proj Manage. 2009, 27(6): 638-648.

[4] A. Kadefors. Trust in project relationships: inside the black box. Int J Proj Manage. 2004, 22(1): 75-82.

[5] W. Wong, S. Cheung, T. Yiu, and H. Pang. A framework for trust in construction contracting. Int J Proj Manage. 2008, 26(8):821-829.

[6] P. Wong, and S. Cheung. Trust in construction partnering: views from parties of the partnering dance. Int J Proj Manage.2004, 22(4): 37-46.

[7] K. Dongus. Control balancing in information systems development offshoring projects. MIS Q. 2013, 37(4): 12111232.

[8] E. Cheung, A. Chan, S. Kajewski. Factors contributing to successful public private partnership projects, comparing Hong Kong with Australia and the United Kingdom. J. Facil. Manag. 2012, 10(1): 45-58.

[9] N. Carbonara, N. Costantino, and R. Pellegrino. Concession period for PPPs: A win-win model for a fair risk sharing. Int J Proj Manage. 2014, 32(7): 1223-1232.

[10] F. Mcfarlan. Portfolio approach to information systems. Harv. Bus. Rev. 1981, 59(5): 142-150.

[11] M. Suprapto,H. Bakker, H. Mooi, and M. Hertogh. How do contract types and incentives matter to project performance. Int J Proj Manage.2016, 34(6): 1071-1087.

[12] S. Liu, and L. Wang. Influence of managerial control on performance in medical information system projects: The moderating role of organizational environment and team risks. Int J Proj Manage.2016, 34(1): 102-116.

[13] Y. Ke, S. Wang, A. Chan, and P. Lam. Preferred risk allocation in China's public-private partnership (PPP) projects. Int J Proj Manage. 2010, 28(5): 482-492.

[14] L. Wen, and B. Ye. Analyses of Mediating Effects: The Development of Methods and Models. Acta Psychologica Sinica.2014, 22(5): 731-745. 